Harvard Data Science Review • Issue 4.1, Winter 2022

\title{
Transforming Hiring and Retention: Mr. Edison Meets AI/ML
}

Maryse Williams ${ }^{1}$

${ }^{1}$ JobMorph, Highland Park, Illinois, United States of America

Published on: Jan 27, 2022

DOI: https://doi.org/10.1162/99608f92.0f97ea03

License: Creative Commons Attribution 4.0 International License(CC-BY 4.0). 
Editor's Note: Maryse Williams, founder and CEO of JobMorph, a job search company that combines automation, artificial intelligence (AI), and personalized services, prompts us to consider a future where AI is used to source talent. Whereas the job search industry has maintained the same parameters for a good candidate since Thomas Edison's time, this article discusses the potential advantages and disadvantages of the adoption of AI, including the kinds of regulations that can lead to success.

Keywords: AI, ML, hiring, retention, human resources, people analytics

\section{Employment Applications and Testing}

A Thomas Edison biography, if written today, might include this:

Ubiquitous to daily life are Edison's phonograph, mimeograph, telegraph, electric pen, vitascope, and carbon telephone transmitter. Today embedded into smartphones, Edison's original wire frames and use cases for these products have undergone an astonishing digital transformation.

This nearly global adoption of Edison's work would surely be unrecognizable to him in its current ideations. Yet Edison could walk today into any organization, small or large, anywhere in the world, and recognize immediately two creations as his own: the job interview and the employment test.

The notion that organizations today source talent like Edison should produce profound planetary panic. Think of this: when Edison invented these tools, the U.S. Bureau of Labor Statistics reported that $1 \%$ of lawyers were women, more than $38 \%$ of the U.S. labor force worked on farms, and 1.75 million U.S. children aged 10-15 were gainfully employed (Fisk, 2001). The landscape is very different today, but business leadership continues to use applications and tests to source talent. What will happen when business leaders deploy today's technologies to source their talent? And tomorrow's?

\section{NexGen Hiring and Retention Technologies}

Consider, for instance, the use of predictive analytics and recommender systems to present career options. Done right, this transformation will likely produce a considerably more inclusive and diverse workforce. With transparent data from employers refining those predictions, enabling a more nuanced understanding of the impact of education, training, certification, and self-development on career success, earnings, unemployment rates, and job satisfaction, this can lead to better individual and managerial decision-making.

An artificial intelligence (AI)-driven enterprise transformation that revolutionizes hiring and retention will create a lasting impact on the world of work, managerial decision-making, and leadership. It will be a future where individuals choose paths with real-time information, advance their education with a clear understanding of impact to their future careers, and select opportunities based on likelihood of success. In the future, real-time 
information about the labor force, integrated with data science and AI, will yield more accurate predictive models to enable better management of human capital. The right person, for the right role, at the right time. This can drive a future with a more stable workforce, with its constituent impacts on gross domestic product, the cost of goods and services, and taxes, as those 11 million jobs unfilled in the United States today (U.S. Bureau of Labor Statistics, 2022) become 950,000 or even 95,000.

As a result, the Thomas Edison biography, written in the future, could include this: 'Edison also invented the job application and the employment test. In an AI-driven world, these are obsolete.'

But should it?

\subsection{Implications of Al}

The answer is an unequivocal 'yes' for some who adopt an almost messianic reverence of AI-powered talent selection. These fervent missionaries often fail to acknowledge that predicting human potential is significantly more complex than predicting clicks on advertising campaigns, default rates on mortgage products, or the likelihood that a particular piece of machinery would need replacing. Wrong decisions or inaccurate predictions in most business analytics applications can result in financial loss; wrong decisions or inaccurate predictions in decisions to hire (or promote) could potentially have life-altering consequences, not just for the individual but for their entire family, and even for generations of their descendants.

Consider the grim realities of what has happened in the past when individuals, organizations, or nations reduce complex human characteristics and behaviors to data points and numbers. Known byproducts of reductionist thinking have in human history included the loss of privacy, the assumption of decision-making by the state, and incredibly poor choices where dollars are overvalued and lives undervalued. So now is the time to ask difficult questions. What provisions should there be for employees to opt out of their employer collecting their personal data about compensation and performance? Should employers be free to share data collected about their employees with external analytics providers without consent? Should there be transparency to the employee about the projected trend line of their potential? And will this trend line of their potential be shared internally? With consent? Without? Externally? To future employers? Credit bureaus? MBA programs?

Maybe with this in mind, the Thomas Edison biography, written in the future, will include this instead:

Edison also invented the job application and the employment test. In the early 21st century individuals, organizations, and nations attempted to use AI to select talent without first developing a full understanding of algorithmic bias and privacy implications. These efforts encountered great resistance from unions, trade associations, and activists. Today, there are regulations to protect employee privacy in much the same way that the early 20th century led to regulations to protect employee safety. 


\section{Acknowledgments}

Deepest appreciation to the Harvard Business Analytics Program.

\section{Disclosure Statement}

Maryse Williams has no financial or non-financial disclosures to share for this article.

\section{References}

Fisk, D. M. (2001). American labor in the 20th century. Compensation and Working Conditions, 6(3), 3-8.

https://www.bls.gov/opub/mlr/cwc/american-labor-in-the-20th-century.pdf

U.S. Bureau of Labor Statistics (2022, February 1). Job openings and labor turnover summary-December 2021 [Press release]. https://www.bls.gov/news.release/jolts.nr0.htm

(C)2022 Maryse Williams. This article is licensed under a Creative Commons Attribution (CC BY 4.0) International license, except where otherwise indicated with respect to particular material included in the article. 